\title{
Research on Stability of Strategic Alliance in Heilongjiang Soybean Processing Industry: an Empirical Study based on AHP and FCE Method
}

\author{
Xiaomei Zhang, Na Liu* and Yang Wang \\ College of Economics and Management, Northeast Agricultural University, \\ Harbin, China \\ liuna19910420@163.com
}

\begin{abstract}
In recent years, as the economic continuous development, market competition has been dramatically increasing. In order to maintain competition advantage, enterprises have to seek for more cooperation. As a new model of cooperation, industry strategic alliance is a significant method for cooperation to get competitive advantage, also increasing the rate of innovation. However, due to a variety of factors, part of the alliance is not stable, failure rate is very high. Heilongjiang province soybean processing industry strategic alliance as one of the best agricultural strategic alliance in China, it is also disturbed by it. In order to ensure the healthy and stable development of the alliance, in this paper, we will draw on relevant literature and expert advice, also field visits to the alliance, finding out the factors affecting the stability of the alliance. Then, AHP and fuzzy comprehensive evaluation method are combined to identify high impact factors, and puts forward specific comments based on the factors identified, thereby enhancing the long-term stable development of the alliance. At the same time, it also laid the foundation for the healthy development of other alliances.
\end{abstract}

Keywords: Soybean processing industry; Strategic alliance; Stability; Influence factor; AHP method

\section{Introduction}

Since the 1990s, the world economy entered a period of rapid development, countries affected by the impact of economic globalization, is experiencing great changes. In the fierce market competition, corporate resources, knowledge and technology have become increasingly demanding. To make enterprises gain a competitive advantage in the market, enterprises entered into a cooperation mode, to achieve risk sharing, resource sharing, new areas together into new markets. Strategic alliance as a new competition pattern of cooperation will rise in the competition of global economic integration. Examples of recent years shows that strategic alliances have become multinationals, particularly in the automotive, electronics and other industries to strengthen the effective strategy of internal competitive advantage. More and more companies embarked on a strategic alliance. Industry and agriculture have also chosen this way. Strategic alliance among them, the agricultural industry as an important carrier of the implementation of technical innovation in our country, since the pilot, continues to grow and develop in exploration.

Heilongiiang Province as a big province of Chinese resource, the agricultural resources reserve rich variety, the soybean processing industry is the most representative. Soybean as our traditional export products, from the beginning of the 1930s, living first in the world production.Soybean processing industry has become the important part of our economy, The quality of soybean processing industry directly affects the social stability of China's economy and rural development.Heilongjiang province is the main origin of 
Chinese soybean, its development has been the focus of other provinces and even the whole country.

In recent years, in order to improve the soybean processing industry of resource optimization and promote the stable development of soybean processing industry, Heilongiiang province set up a strategic alliance of soybean processing industry. Through the establishment of alliance,soybean processing industry can not only reduce the huge risk of explore new areas and develop new technologies, can also combine the capital,technology and core competitiveness of alliance partners, thereby expanding the market share of soybean processing industry, obtaining the speed of economic effects. But Heilongiiang Province soybean processing industry strategic alliance in the initial stage, development speed is very fast, from 2009 to 2014, alliance members from 19 increased to 50. However, due to various reasons, the instability of the alliance has been maintained at a high level.For example, profit distribution mechanism currently exists imperfect operation in the process of alliance, it has seriously hampered the healthy development of soybean processing industry in Heilongiiang province.Therefore, how to optimize and improve the operation of the soybean processing industry strategic alliances and exclude running instability are the problems that must be resolved.

\section{Literature Review}

\subsection{Strategic Alliance}

Strategic alliance was first proposed by the DEC President Jan Holland and management experts Roger Nigel. But on this concept, the current domestic and foreign scholars have different interpretations.Modic and Potter(1988) think the strategic alliance means a loose relation network organization that alliance body based on cost efficiency and competitive advantage and other factors established.They believe that alliance should complement each other, risk-sharing[1]. Teece (1992) argues that the strategic alliance is the cooperative activities, it have two or more than two partners to achieve the trategic objectives that resource sharing and something complementary. After the 1990s, scholars no longer focus only on traditional lateral strategic alliance between enterprises, but the shift attention to vertical industry technology alliance[2]. Yoshino and Rangan (1995) believes that the type of inter-enterprise relations have many forms, in addition to mergers and acquisitions and the traditional contract, the other can be classified as strategic alliances. Specifically, the alliance is divided into three types, namely non-traditional contract (non-equity-based contracts), minority equity alliances and joint ventures[3]. Parkhe (1993) through the use of game theory, combined with transaction costs on the strategic alliance to carry out in-depth study. He pointed out that the payment structure of the alliance, the shadow of the future and the number of participants has a significant impact on the performance of the alliance[4].

\subsection{Stability of Strategic Alliance}

The instability of strategic alliance was revealed by Franko in 1971.Yet until 1990s, the instability of strategic alliance just attracted the attention of the theoretical circle.The research on the stability of strategic alliance can be divided into three stages:The first phase ended in the 1990s. The research focused on tracking investigation and statistical analysis, lacking of in-depth research for the alliance instability or stability. Beamish (1985) and Kogut (1988) began to pay attention to the instability of the strategic alliance[5].Porter (1990) points out that the alliance is only a transitional form in its value chain theory [6].Until 1991, Bleeke and Ernst conducted a follow-up survey of the global strategic alliance.The result shows that the strategic alliance is few, only about $30 \%$.Most of the failure of the alliance to the merger or the disintegration of the end[7].The second stage from the beginning of 1990 s to the end of the 90 's, the scholars which mainly from 
the transaction cost theory, game theory and resource dilemma theory analyzes the instability of alliance. Its representative figures are mainly Hennart (1988), Parkhc (1993), Madhok and Tallman (1998).The third stage began in 1997, Inkpen and Beamish make a precise definition of the instability of the strategic alliance, and the stability of the alliance is defined in theory[8].In 1998, Spekman, Isabella and Macavoy have a classic summary of the research of strategic alliance,and it is pointed out that the stability of the alliance will become the main direction of the future research[9]. Since then, the stability of the strategic alliance has entered the third stage, The stability of the alliance is really beginning to receive the attention of the theoretical circle. Zeng and Chen (2003) study the latest achievements of the stability of strategic alliance, they constructed a relatively complete framework of sociological analysis through social dilemma theory.They emphasize the important role of trust and other social factors[10]. From 2000 to the present, the research on the stability of the strategic alliance has gradually matured. Jiang, Li and Gao (2008) improved the stability of the understanding to the dynamic angle,they point out that the stability of the alliance should have the double meaning of the result and the process, alliance stability is the foundation for the successful operation and development of the alliance [11]. Wen Tang(2013) thought the profit distribution is one of the important factors which influence the stability of industrial alliance[12]. Yan $\mathrm{Xu}$ (2015)applies stochastic evolutionary game theory to analyzing the stability of cooperation among members against external opportunism in a multi-firm alliance[13].

\subsection{Summary}

The scholars at home and abroad have a mature research on the strategic alliance and its stability. They discussed the definition, formation of motivation, theoretical foundation and mode selection of strategic alliance from a different perspective, they also study the stability of the alliance comprehensive and specific from many aspects. As time goes on, scholars have very in-depth research from all areas of industry strategic alliance,but the study on stability of soybean processing industry strategic alliance is seldom. So author study this issue, and research the strategic alliance stability in soybean processing industry.

\section{Analysis of Factors Affecting Stability}

Soybean processing industry strategic alliance (hereinafter referred to soybean alliance is still in the initial stage, the development is not yet stable.Through the field research found that the soybean alliance has many problems, these problems affect the stable development of soybean alliance. After the conclusion, the influence factors are divided into two parts: external environmental factors and internal factors.

\subsection{External Environmental Factors}

External environmental factors mainly include political factors, economic factors and market factors. Political factors are government intervention, laws and regulations, they can force and influence the various organizations and individuals in the society. The government, as a public utility, is likely to be forced to intervene in the soybean alliance, which affects stable development of soybean alliance. Economic factors mainly refer to the health degree of the national capital market and the fund source of the strategic alliance. Market factors have a greater impact on the stability of the alliance. In a way, the market allocation of resources, market maturity, market demand state determines the survival and development of alliance members. 


\subsection{Alliance Internal Factors}

By drawing on literature and field research, summed up the internal factors that influence the stability of soybean alliance includes matching members, organizational culture, specific assets investment, resource dependence, the degree of information communication, Benefit distribution mechanisms and internal management level.

\section{Construction of AHP-FCE Model and Evaluation of Alliance Stability}

This paper used the method of AHP-FCE to establish stability evaluation model of soybean alliance, and through this method to assess the various factors that influence the stability of soybean alliance, then find out the factors which influence the degree and put forward some suggestions for it, so as to enhance the stability of soybean alliance.

\subsection{Identify Factor Set $u$ and Comment Set $v$}

Factor set refers to the set of evaluation indicators. If the evaluation index has $\mathrm{m}$, it is expressed as: $\mathrm{U}=\{\mathrm{u} 1, \mathrm{u} 2, \ldots, \mathrm{Um}\}$.Comment set is a collection of degrees, the evaluation index is divided into different levels of good or bad in it. We often use the method of rating. Comment is divided into seven levels, namely $V=\{$ best, better, good, medium, poor, poorer,poorest $\}$, and give the value of the elements in the collection, $\mathrm{V}=\{1,3,5,7,9,11,13\}$, in order to achieve fuzzy correspondence relationship.

\subsection{Determine the Weight Distribution}

In the various factors affecting the stability of soybean alliance, each element has a different proportion, and the degree of each factor affecting the stability of alliance are different.In this paper, we are using a method that combining quantitative and qualitative analysis to calculate the weight of each factor.It is divided into the following several parts:Construction hierarchy model, Structure judgment matrix, Hierarchical single ranking, Consistency check, Hierarchical total ranking.

\subsubsection{Constructing Hierarchical Model:}

According to the analysis of Factors Affecting Stability,we can get that there are 3external environmental factors and 7 internal factors. The evaluation index system of stability of soybean alliance was constructed as table 1 .

Table 1. Stability Evaluation Index System of Soybean Alliance

\begin{tabular}{|c|c|c|}
\hline Level A & Level B & Level C \\
\hline \multirow{10}{*}{$\begin{array}{c}\text { Evaluation Index of } \\
\text { Stability of Soybean } \\
\text { Alliance U }\end{array}$} & \multirow{3}{*}{$\begin{array}{c}\text { External environmental } \\
\text { factors } U_{1}\end{array}$} & Political factor $U_{11}$ \\
\hline & & Economic factor $\mathrm{U}_{12}$ \\
\hline & & Market factor $\mathrm{U}_{13}$ \\
\hline & \multirow{7}{*}{ Alliance internal factors $U_{2}$} & Specific asset investment factors $\mathrm{U}_{21}$ \\
\hline & & Member matching factor $\mathrm{U}_{22}$ \\
\hline & & $\begin{array}{l}\text { Information communication level factor } \\
\qquad U_{23}\end{array}$ \\
\hline & & Organizational culture factors $\mathrm{U}_{24}$ \\
\hline & & $\begin{array}{l}\text { Benefit Distribution Mechanism factors } \\
\qquad U_{25}\end{array}$ \\
\hline & & Internal management level factor $\mathrm{U}_{26}$ \\
\hline & & Resource dependence factor $\mathrm{U}_{27}$ \\
\hline
\end{tabular}




\subsubsection{Structure Judgment Matrix:}

Generally, in order to distinguish the strength of the stability between two factors,we will adopt certain standards of judgment, namely 1-9 and its reciprocal scaling, to indicate the relative importance, as the Table2. After a number of experts to fill in the relative importance of factors questionnaire of soybean alliance stability, such as Table3, Table4 and Table5, structure judgment matrix, and carry on the summary.

Table 2. The Meaning of 1- 9 Scale

\begin{tabular}{|c|c|}
\hline Scale $\mathrm{a}_{\mathrm{ij}}$ & Meaning \\
\hline 1 & Two factors are equally important of a certain nature \\
\hline 3 & The $\mathrm{i}$ factor is slightly more important than the $\mathrm{j}$ factor \\
\hline 5 & The $\mathrm{i}$ factor is significantly more important than the $\mathrm{j}$ factor \\
\hline 9 & The $\mathrm{i}$ factor is more important than the $\mathrm{j}$ factor \\
\hline $2,4,6,8$ & The I factor is extremely important than the $\mathrm{j}$ factor \\
\hline $1,1 / 2,1 / 3, \ldots 1 / 9$ & Intermediate value of the two-level judgment \\
\hline & The important ratio of I factor and $\mathrm{j}$ factor is opposite to that \\
mentioned above.
\end{tabular}

Table 3. Main Factor Relative Importance Questionnaire

\begin{tabular}{|l|l|l|}
\hline & External Environmental Factors & Alliance Internal Factors \\
\hline External Environmental Factors & 1 & $1 / 3$ \\
\hline Alliance Internal Factors & 3 & 1 \\
\hline
\end{tabular}

Table 4. External Environmental Sub-factors Relative Importance Questionnaire

\begin{tabular}{|c|c|c|c|}
\hline & Political Factor & Economic Factors & Market Factors \\
\hline Political Factor & 1 & $1 / 2$ & $1 / 3$ \\
\hline Economic Factors & 2 & 1 & $1 / 2$ \\
\hline Market Factors & 3 & 2 & 1 \\
\hline
\end{tabular}


Table 5. Alliance Internal Sub-factors Relative Importance Questionnaire

\begin{tabular}{|c|c|c|c|c|c|c|c|}
\hline & $\begin{array}{c}\text { Specific } \\
\text { asset } \\
\text { investme } \\
\text { nt }\end{array}$ & $\begin{array}{l}\text { Member } \\
\text { matching }\end{array}$ & $\begin{array}{c}\text { Information } \\
\text { communicat } \\
\text { ion level }\end{array}$ & $\begin{array}{l}\text { Organizati } \\
\text { onal } \\
\text { culture }\end{array}$ & $\begin{array}{c}\text { Benefit } \\
\text { Distribution } \\
\text { Mechanism }\end{array}$ & $\begin{array}{c}\text { Internal } \\
\text { manageme } \\
\text { nt level }\end{array}$ & $\begin{array}{c}\text { Resource } \\
\text { dependence }\end{array}$ \\
\hline $\begin{array}{l}\text { Specific asset } \\
\text { investment }\end{array}$ & 1 & $1 / 5$ & $1 / 7$ & 2 & $1 / 9$ & $1 / 3$ & $1 / 3$ \\
\hline $\begin{array}{l}\text { Member } \\
\text { matching }\end{array}$ & 5 & 1 & $1 / 2$ & 7 & $1 / 2$ & 2 & 1 \\
\hline $\begin{array}{c}\text { Information } \\
\text { communication } \\
\text { level }\end{array}$ & 7 & 2 & 1 & 9 & $1 / 2$ & 2 & 5 \\
\hline $\begin{array}{c}\text { Organizational } \\
\text { culture }\end{array}$ & $1 / 2$ & $1 / 7$ & $1 / 9$ & 1 & $1 / 9$ & $1 / 5$ & $1 / 5$ \\
\hline $\begin{array}{c}\text { Benefit } \\
\text { Distribution } \\
\text { Mechanism }\end{array}$ & 9 & 2 & 2 & 9 & 1 & 7 & 7 \\
\hline $\begin{array}{c}\text { Internal } \\
\text { management } \\
\text { level }\end{array}$ & 3 & $1 / 2$ & $1 / 2$ & 5 & $1 / 7$ & 1 & $1 / 3$ \\
\hline $\begin{array}{c}\text { Resource } \\
\text { dependence }\end{array}$ & 3 & 1 & $1 / 5$ & $1 / 5$ & $1 / 7$ & 3 & 1 \\
\hline
\end{tabular}

\subsubsection{Hierarchical Single Ranking and Consistency Check:}

In this paper, the root method is used to calculate the weight of each level. First of all, the corresponding value of judgment matrix A multiplied in turn, and then open $n$-th power.We can get $\underline{\omega}_{i}=\left(\underline{\omega}_{1}, \underline{\omega}_{2}, \cdots, \underline{\omega}_{\mathrm{n}}\right)$.Then the matrix is normalized, We can get $\omega_{i}=\left(\omega_{1}, \omega_{2}, \cdots, \omega_{n}\right)$. Finally, we have to check the consistency of the results obtained. If the consistency check is passed, ${ }^{\omega_{i}}$ is the weight vector.

Normalized processing formula: $\omega_{i=} \frac{\frac{\omega_{i}}{\sum_{j=1}^{n} \frac{\omega_{j}}{}}}{{ }^{n}}$

Consistency check : $C . I=\frac{\lambda_{\max }-n}{n-1}$.

C.I is smaller, the greater consistency. But considering the consistency bias is likely to be caused by random reasons, usually, we will compare C.I with mean random consistency index R.I when the consistency check.

Then, we can obtain inspection number $C . R=\frac{C . I}{R . I}, C . R<0.1$, We think it through consistency inspection. Among them, R.I is related to the end of judgment matrix, order is bigger then random deviation of Consistency is bigger. The general data are as follows: Table 6 . 
Table 6 . Random Consistency Index R.I Value

\begin{tabular}{|c|c|c|c|c|c|c|c|c|c|c|c|c|}
\hline Dimension & 1 & 2 & 3 & 4 & 5 & 6 & 7 & 8 & 9 & 10 & 11 & 12 \\
\hline$R . I$ & 0 & 0 & 0.52 & 0.89 & 1.12 & 1.26 & 1.36 & 1.41 & 1.46 & 1.49 & 1.52 & 1.54 \\
\hline
\end{tabular}

According to the above process, can get:

$$
A_{1}=\left[\begin{array}{cc}
1 & 1 / 3 \\
3 & 1
\end{array}\right] \Rightarrow \omega_{1}=\left(\begin{array}{ll}
0.25 & 0.75
\end{array}\right)
$$

Obviously meet the conformance requirements.

$$
\begin{gathered}
A_{2}=\left[\begin{array}{ccc}
1 & 1 / 2 & 1 / 3 \\
2 & 1 & 1 / 2 \\
3 & 2 & 1
\end{array}\right] \Rightarrow \omega_{2}=\left(\begin{array}{lll}
0.1634 & 0.2790 & 0.5396
\end{array}\right) \\
\lambda_{\max }=3.0092 \\
C . I=0.0046 \quad \text { R.I }=0.0052 \quad C . R=0.0088<0.1
\end{gathered}
$$

Meet the conformance requirements.

$$
\begin{aligned}
& A_{3}=\left[\begin{array}{ccccccc}
1 & 1 / 5 & 1 / 7 & 2 & 1 / 9 & 1 / 3 & 1 / 3 \\
5 & 1 & 1 / 2 & 7 & 1 / 2 & 2 & 1 \\
7 & 2 & 1 & 9 & 1 / 2 & 2 & 5 \\
1 / 2 & 1 / 7 & 1 / 9 & 1 & 1 / 9 & 1 / 5 & 1 / 5 \\
9 & 2 & 2 & 9 & 1 & 7 & 7 \\
3 & 1 / 2 & 1 / 2 & 5 & 1 / 7 & 1 & 1 / 3 \\
3 & 1 & 1 / 5 & 1 / 5 & 1 / 7 & 3 & 1
\end{array}\right] \\
& \Rightarrow \omega_{3}=\left(\begin{array}{lllllll}
0.0330 & 0.1409 & 0.2428 & 0.0224 & 0.3906 & 0.0778 & 0.0925
\end{array}\right) \\
& \lambda_{\max }=7.2939 \text { C.I }=0.0490 \quad \text { R.I }=1.36 \quad C . R=0.036<0.1
\end{aligned}
$$

Meet the conformance requirements.

\subsubsection{Hierarchical Total Ranking:}

After the hierarchical single ranking, Hierarchical Total Ranking are carried out. Of course, we also need consistency check.

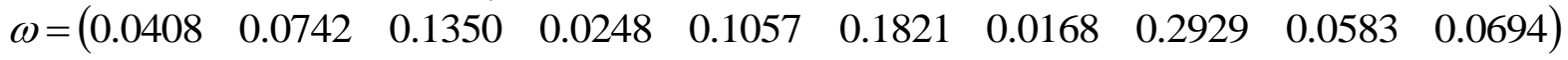
$C . I=0.0379 \quad R . I=1.0330 \quad C . R=0.0367<0.1 \quad$ Meet the conformance requirements.

According to the summary and finishing above calculation results, we can build the soybean alliance stability evaluation index system, as shown in Table 7 , and indicate the weight of each index. 
Table 7. Stability Comprehensive Evaluation Index System of Soybean

\begin{tabular}{|c|c|c|}
\hline Classification & Evaluation Index & Weights \\
\hline \multirow{3}{*}{$\begin{array}{c}\text { External environmental } \\
\text { factors } 25 \%\end{array}$} & Political Factor & 4.08 \\
\cline { 2 - 3 } & Economic Factor & 7.42 \\
\cline { 2 - 3 } & Market Factors & 13.50 \\
\hline \multirow{4}{*}{$\begin{array}{c}\text { Alliance internal factors } \\
75 \%\end{array}$} & Specific asset investment & 2.48 \\
\cline { 2 - 3 } & Member matching & 10.57 \\
\cline { 2 - 3 } & $\begin{array}{c}\text { Information communication } \\
\text { level }\end{array}$ & 18.21 \\
\cline { 2 - 3 } & Organizational culture & 1.68 \\
\cline { 2 - 3 } & $\begin{array}{c}\text { Benefit Distribution } \\
\text { Mechanism }\end{array}$ & 29.29 \\
\cline { 2 - 3 } & Internal management level & 5.83 \\
\cline { 2 - 3 } & Resource dependence & 6.94 \\
\hline
\end{tabular}

\subsection{Construction Fuzzy Relationship}

Through visits Soybean Processing Industry alliance, 20 alliance members and experts to be selected to fill in the questionnaire about soybean alliance stability, then, recycling and aggregate to form a table, as shown in Table 8.

Table 8. Soybean Alliance Stability Summary

\begin{tabular}{|c|c|c|c|c|c|c|c|}
\hline Comment Index & best & better & good & medium & poor & poorer & poorest \\
\hline Political Factor & 0 & 4 & 7 & 4 & 2 & 3 & 0 \\
\hline Economic Factor & 1 & 3 & 2 & 7 & 3 & 2 & 2 \\
\hline Market Factors & 2 & 3 & 4 & 5 & 4 & 2 & 0 \\
\hline Specific asset investment & 0 & 3 & 5 & 10 & 2 & 0 & 0 \\
\hline Member matching & 2 & 2 & 5 & 6 & 1 & 2 & 3 \\
\hline $\begin{array}{c}\text { Information communication } \\
\text { level }\end{array}$ & 0 & 1 & 1 & 4 & 5 & 3 & 6 \\
\hline Organizational culture & 0 & 1 & 4 & 5 & 4 & 3 & 2 \\
\hline $\begin{array}{c}\text { Benefit Distribution } \\
\text { Mechanism }\end{array}$ & 1 & 2 & 2 & 3 & 5 & 4 & 3 \\
\hline Internal management level & 0 & 2 & 2 & 4 & 3 & 6 & 3 \\
\hline Resource dependence & 0 & 3 & 2 & 4 & 4 & 5 & 2 \\
\hline
\end{tabular}

The data in the table are the feedback from the alliance members and experts. According to this table to construct the fuzzy judgment matrix, judgement matrix is mainly to judge two main factors that affect the stability of the alliance.The main process is as follows:

$$
C_{1}=\left[\begin{array}{ccccccc}
0 & 0.2 & 0.35 & 0.2 & 0.1 & 0.15 & 0 \\
0.05 & 0.15 & 0.1 & 0.35 & 0.15 & 0.1 & 0.1 \\
0.1 & 0.15 & 0.2 & 0.25 & 0.2 & 0.1 & 0
\end{array}\right]
$$




$$
C_{2}=\left[\begin{array}{ccccccc}
0 & 0.15 & 0.25 & 0.5 & 0.1 & 0 & 0 \\
0.1 & 0.1 & 0.25 & 0.3 & 0.05 & 0.1 & 0.15 \\
0 & 0.05 & 0.05 & 0.2 & 0.25 & 0.15 & 0.3 \\
0 & 0.05 & 0.2 & 0.25 & 0.2 & 0.15 & 0.1 \\
0.05 & 0.1 & 0.1 & 0.15 & 0.25 & 0.2 & 0.15 \\
0 & 0.1 & 0.1 & 0.2 & 0.15 & 0.3 & 0.15 \\
0 & 0.15 & 0.1 & 0.2 & 0.2 & 0.25 & 0.1
\end{array}\right]
$$

Final evaluation results:

$$
\begin{aligned}
& V_{1}=\omega_{2} C_{1} V^{\mathrm{T}}=6.5133 \\
& V_{2}=\omega_{3} C_{2} V^{\mathrm{T}}=7.7200
\end{aligned}
$$

Comprehensive evaluation $V=7.4$

According to the above results show that $V_{1}<V_{2}$, it shows that the instability of alliance interior factors is greater than the external factors. 6.5133 in the middle of good and medium, it has a minor effect on the stability of the alliance. 7.7200 belong to the middle of poor and medium, it has a great influence on the stability of the alliance. Comprehensive evaluation $V=7.4$,it shows that the stability of Heilongjiang province soybean processing industry strategic alliance is poor. At the same time, from the weight of factors can be seen that benefit distribution mechanism, information communication level, member matching and market factors affect the stable development of the alliance to a large extent.

\section{Conclusion and Suggestion}

According to the analysis of the results, alliance internal factors can affect the stability of the alliance even more. Overall, the weight of benefit distribution mechanism, information communication level, and member matching and market factors is bigger, the influence is stronger. So, we can take measures from the following four aspects to ensure the healthy development of Heilongjiang province soybean processing industry strategic alliance. The first, it will accurate identification of market opportunities. Alliance need to identify opportunities quickly, grasps timeliness, determine where the market is, and identify market demand and analysis how to innovate technology to ensure their own competitiveness. The second seek alliance partners based on core competencies. Objectively assess their core competencies and seek same or complementary enterprise. The third, make effective cooperation norms. Cooperation norm is the fundamental basis for regulating the behavior of alliance members. Specification should include the alliance objectives, forms, steps, determine alliances center, how to distribute interests, how to effective cooperation, punishment and so on. Specification must be the result of alliance members discussed. It should achieve a balanced, trust each other, respect each other, clear objectives, defined specifications. The fourth, open communication positions, improve alliance centripetal force. Alliance need to establish alliance internal liaison officers. liaison officers often visits between members of the unit, need to collect and collate information and then share it. At the end of return visit, liaison officers should do a good job of feedback. Alliance need to to set Information Network Reporter. They should always pay attention to the dynamic of whole country and even the whole world.They need to collate and report the information to the alliance in time to prevent all waste human and material resources opportunities. 


\section{References}

[1] M. Potter, "Inventure Divorce in the Multinational Company", Columbia Journal of Word Business, vo1. 6, no. 3, (1988), pp. 13-22.

[2] K. Teece, "Competition and Cooperation:Striking the Right Balance", California Management Review, vol. 31, (1992), pp. 25-37.

[3] M. Y. Yoshino and U. S. Rangan, "Strategic Alliances-An Entrepreneurial Approach to Globalization", Harvard Business Review Press, vo1. 29, no. 4, (1995), pp. 272-287.

[4] A. Parkhe, "Strategic Alliance Structuring:A Game Theoretic and Transaction Cost Examination of Inter-Firm Alliances", The Academy of Management Journal, vol. 36, no. 4 , (1993), pp. 794-829.

[5] B. Kogut, "Joint ventures:Theoretical and empirical perspectives", Strategic Management Journal, vo1. 4, no. 9, (1988), pp. 319-332.

[6] M. E. Porter, "Competitive Advantage:Creating and Sustaining Superior Performance", Free Press, (1990).

[7] J. Bleeke and D. Ernst, "The Way to Win in Cross-Border Alliances", Harvard Business Review, vo1. 69, no. 6, (1991), pp. 127-135.

[8] A. Inkpen and P. Beamish "Knowledge, bargaining power,and the instability of international joint venture", The Academy of Management Journal, vo1. 22, no. 1, (1997), pp. 177-202.

[9] S. Robert, E. Isabella and L. A. Macavoy, "Creating strategic, alliances which endure", Long Range Planning, vol. 29, no. 3, (1998), pp. 346-357.

[10] M. Geng and X. Chen. "Achieving cooperation in multiparty alliances: a social dilemma approach to partnership management", The Academy of Management Review, vol. 28, no. 4, (2003), pp. 587-605.

[11] X. Jiang and L. Sanxing, "The stability of strategic alliances:Characteristics,factors and stages", Journal of International Management, vo1. 14, (2008), pp. 173-189.

[12] W. Tang, "Research on Benefits Distribution Model of Industry Technology Innovation Strategic Alliance Based on Investment of Resource and Risk Compensation", International Asia Conference on Industrial Engineering and Management Innovation, (2013).

[13] Y. Xu, "A stochastic evolutionary game perspective on the stability of strategic alliances against external opportunism", Journal of Systems Science and Complexity, vo1. 28, no. 8, (2015), pp. 978-996. 